\title{
Type A aortic dissection in pregnant patients with fibrillin-1 gene mutations: Two case reports and a literature review
}

\author{
YUANLI LEI ${ }^{1}$, ZHELONG JIANG ${ }^{2}$, JIAOZHEN CHEN ${ }^{3}$, DONGSHENG WANG ${ }^{1}$, \\ GUANGLIANG HONG ${ }^{1}$ and SHOUQUAN CHEN ${ }^{1}$
}

\author{
${ }^{1}$ Department of Emergency Medicine, The First Affiliated Hospital of Wenzhou Medical University, \\ Wenzhou, Zhejiang 325000; ${ }^{2}$ Department of Emergency Medicine, Hangzhou First People's Hospital, \\ Nanjing Medical University, Hangzhou, Zhejiang 310000; ${ }^{3}$ Department of Electrocardiogram, \\ Wenzhou People's Hospital, Wenzhou, Zhejiang 325000, P.R. China
}

Received March 28, 2018; Accepted July 20, 2018

DOI: $10.3892 / \mathrm{etm} .2018 .6761$

\begin{abstract}
In acute aortic dissection (AD) in pregnancy, increased cardiovascular stress due to pregnancy is an important factor leading to an emergent aortic event. It is rare but often results in a devastating event for both the pregnant patient and the foetus. Two cases of acute AD (Stanford type A) in pregnant females are presented in the present study. The patients were diagnosed via echocardiography, and the diagnosis was confirmed with computed tomography angiography prior to aortic surgery. Up to 50\% of ADs in pregnancy occur in patients with fibrillin-1 (FBN1) gene mutations. The FBN1 gene was sequenced in both patients, and notable, novel pathogenic mutations of FBN1 were identified in both patients. A literature review was also performed on available diagnostic imaging and other measurements regarding $\mathrm{AD}$ during pregnancy. The authors suggest that the relevant content may have important clinical implications in raising disease awareness, arranging test rationally and choosing an intervention method.
\end{abstract}

\section{Introduction}

In acute aortic dissection (AD) in pregnancy, increased cardiovascular stress due to pregnancy is an important factor leading to an emergent aortic event $(1,2)$. It is very rare with an annual incidence rate of 5.5 per million maternities in the US (among $6,566,826$ pregnancies in 4,933,697 females) and 0.5 per million maternities in Europe (341,381 females were followed up after 10 years) $(3,4)$. However, AD often results in a devastating event for both the pregnant woman and the foetus (5-8).

Correspondence to: Professor Shouquan Chen, Department of Emergency Medicine, The First Affiliated Hospital of Wenzhou Medical University, 2 Fuxue Road, Wenzhou, Zhejiang 325000, P.R. China

E-mail: csq@wzhosptal.cn

Key words: aortic dissection, pregnant, diagnostic imaging, fibrillin-1 gene, case report
The mortality of AD prior to admission is $21.4 \%$, which rises to $60.7,75.0$ and $85.7 \%$ if the onset of symptoms occurs 1 , 2 days and 1 week, respectively, prior to admission (9). Once a patient is diagnosed with a Stanford type A dissection (10), emergency surgery should be recommended according to the gestational age in weeks, with the aortic repair and delivery method decided prior to surgery $(7,10,11)$. The present report details two cases of acute AD (Stanford type A) in pregnant women. Both patients were diagnosed by echocardiography, and the diagnosis was confirmed by computed tomography (CT) angiography prior to aortic surgery. The first patient underwent aorta repair followed by caesarean section, and the second patient underwent caesarean section followed by aorta repair. In the first case, the mother survived, but the foetus succumbed. In the second case, both the mother and infant survived. Up to $50 \%$ of ADs in pregnancy occur in patients with fibrillin-1 (FBN1) gene mutations $(1,7,8,11)$. Marfan syndrome, aortic root enlargement, bicuspid aortic valve disease and hypertension are also risk factors for AD in pregnancy $(1,3,7)$. The FBN1 gene was sequenced in both patients, and notably, novel pathogenic mutations of FBN1 were identified in both patients. The literature on available diagnostic imaging, intervention and prognosis of $\mathrm{AD}$ in pregnancy was also reviewed. These findings may have important clinical implications.

\section{Case report}

Case one. A 31-year-old female (gravida 5, para 1; height, $165 \mathrm{~cm}$; weight, $58 \mathrm{~kg}$ ) presented in the 26th week of pregnancy to The First Affiliated Hospital of Wenzhou Medical University (Wenzhou, China) in August 2017 with frequent vomiting and epigastric pain for $4 \mathrm{~h}$ and $30 \mathrm{~min}$. The pain was described as continuous, 10/10 in severity, without radiating pain, and with no association to movement, diet or breathing. Associated symptoms included nausea, frequent vomiting and sweating. The patient had no known risk factors and no family history of aortic dissection.

The patient underwent a routine check-up, which indicated a normal mental status and vital signs were within the normal range on admission (temperature, $37^{\circ} \mathrm{C}$; blood pressure, $118 / 55 \mathrm{mmHg}$; heart rate, 78 beats/min; respiratory 
rate, 20 breaths/min with $96 \% \mathrm{SpO}_{2}$ in room air). Both lungs sounded clear with no obvious rales, the heart sounded normal and the epigastric district was tender, but without rebound pain. The paediatrician reported that the foetus's vital signs were stable. The laboratory data indicated the following: White blood cells, $16.72 \times 10^{9} / 1$ (normal range, 3.50-9.50×10 $/ 1$ ); D-Dimer: $>20 \mathrm{mg} / \mathrm{l}$ (normal range, 0.00-0.50 mg/l); bicarbonate, $14.9 \mathrm{mmol} / 1$ (normal range, 21.4-27.3 $\mathrm{mmol} / \mathrm{l}$ ); and urine ketone body, strong positive (normal range: Negative). Normal values were described previously (12-14). Amylase, troponin I, aminotransferase, creatinine, brain natriuretic peptide, blood $\mathrm{pH}$ and $\mathrm{PaO}_{2}$ were all normal. An electrocardiogram, abdominal ultrasound, and chest and abdominal CT were all normal, except for the presence of the foetus. The patient was diagnosed with acute gastritis and was initially treated with $40 \mathrm{mg}$ esomeprazole magnesium (AstraZeneca PLC, Cambridge, UK) to protect the stomach, 4,000 mg ceftazidime (GlaxoSmithKline plc, Brentford, UK) to treat the infection and a fluid challenge. At 5 days following this prescription, the patient's symptoms improved, and the laboratory data were almost normal. The patient was planned to be discharged at this time. However, transthoracic echocardiography revealed an AD (Stanford type A) affecting the entire thoracic aorta with torrential aortic regurgitation, without mediastinal haematoma or pleural effusion (Fig. 1). The chest CT angiography revealed a Stanford type A AD (DeBakey type I) from the level of the Valsalva sinuses to the distal ascending aorta involving the right coronary orifice (Fig. 2A).

The patient received ascending and descending aorta and total arch replacement with cardiopulmonary bypass (Fig. 2B) for $\mathrm{AD}$ followed by a caesarean section, delivering a male infant who had succumbed in utero. A sequencing peak map for FBN1 is presented in Fig. 3, and the results of the genetic tests were as follows: The outcome of actin, aortic smooth muscle (ACTA2) was negative; FBN1 was mutated at exon 16, c. 1875 T > C (p. Asn625Asn), exon 56, c. 6855 T > C (p. Asp2285Asp), and exon 59, c. $7240 \mathrm{C}>\mathrm{T}$ (p. Arg2414 Termination codon) (Table I). Exon 59, c. 7240 C > T (p. Arg2414 Termination codon) was the pathogenic mutation (Fig. 3A). Following 5 days in the intensive care unit, the patient was transferred to the general ward and uneventfully discharged on postoperative day 21 .

Case two. A 32-year-old female (gravida 1, para 0) with a gestational age of 34+1 weeks was referred to the emergency room of Hangzhou First People's Hospital (Hangzhou, China) in September 2017 due to an acute onset of back pain for $1 \mathrm{~h}$. The patient described the pain as continuous, 10/10 in severity, without radiating pain, with nausea, vomiting and dyspnoea, severe sweating and hypotension. The pain occurred on the way home following a prenatal examination. The patient's medical history included an atrial septal defect repair at the age of 17 years and scoliosis for 20 years; in addition, the patient's mother had succumbed to AD at the age of 30 years.

On arrival the patient was conscious. The heart rate was 115 beats/min, blood pressure was 78/45 mmHg, respiratory rate was 24 breaths/min, oxygen saturation was $97 \%$ on room air, and temperature was $36.0^{\circ} \mathrm{C}$. The patient was $158 \mathrm{~cm}$ tall and weighed $52 \mathrm{~kg}$. Both lungs sounded clear without obvious rales. The heartbeat was weak, both lower limbs exhibited

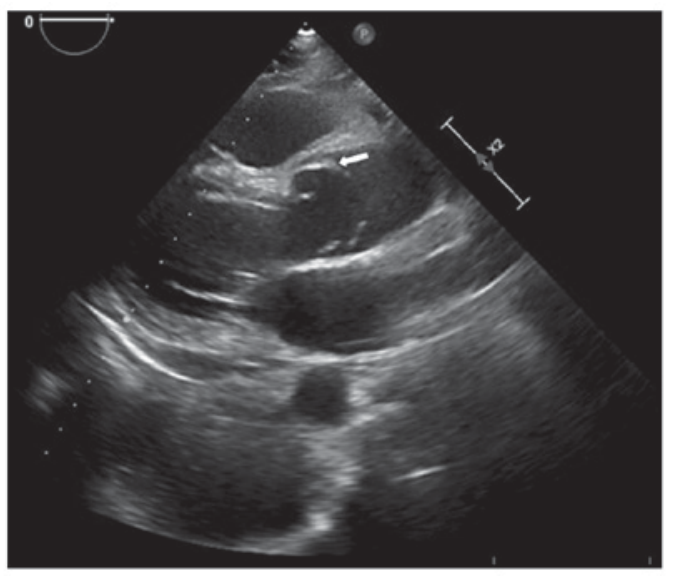

Figure 1. Transesophageal echocardiogram presenting Stanford type A aortic dissection with intimal flap (left arrow).

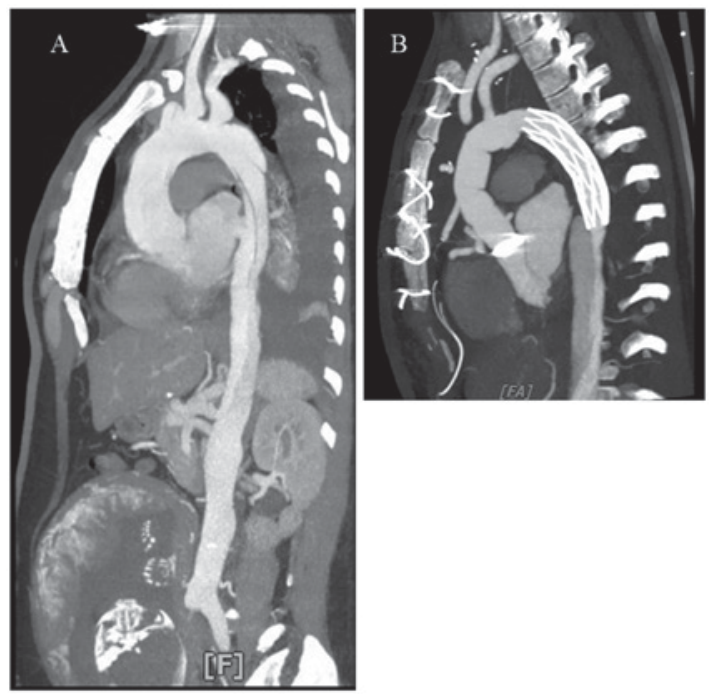

Figure 2. Computed tomography images of a 31-year-old female who sustained an acute Stanford Type A aortic dissection (A) prior to and (B) following surgery at 26 weeks of gestation.

slight oedema, and the abdomen was protuberant due to the gravidity. An electrocardiogram indicated a sinus rhythm with a rate of 115 beats/min and signs of ischaemic changes (Fig. 4). The laboratory data demonstrated the following: Serum lactate, $3.9 \mathrm{mmol} / 1$ (normal range, 1.0-2.5 mmol/l); D-Dimer, 1,400 $\mu \mathrm{g} / 1$ (normal range, $0.0-1,000.0 \mu \mathrm{g} / \mathrm{l}$ ); and values within the normal ranges for creatine kinase isozymes, troponin I, serum creatinine, aminotransferase and bilirubin tests. The transthoracic echocardiography was immediately examined. It revealed that the diameter of the ascending aorta was $45 \mathrm{~mm}$ at the sinotubular junction and a zonal echo in the ascending aorta involving the coronary orifice with torrential aortic regurgitation, without mediastinal haematoma or pleural effusion. The foetal ultrasound was normal. The CT angiography was checked to confirm a Stanford type A AD (DeBakey type II; Fig. 5). The obstetrics, cardiac anaesthesiology and thoracic surgery teams immediately performed an emergency caesarean section and a modified Bentall procedure. The results of genetic tests were as follows: The outcome of ACTA2 was negative; FBN1 was mutated at 
Table I. Mutations in the FBN1 and ACTA2 genes of the present patients.

\begin{tabular}{|c|c|c|c|c|c|c|}
\hline Patient & $\begin{array}{c}\text { Age } \\
\text { (years) }\end{array}$ & $\begin{array}{l}\text { Gestation } \\
\text { (weeks) }\end{array}$ & Gene & $\begin{array}{c}\text { Genetic } \\
\text { sub regions }\end{array}$ & Nucleotide changes & Amino acid changes \\
\hline \multirow[t]{5}{*}{ Case one } & \multirow[t]{5}{*}{31} & \multirow[t]{5}{*}{26} & \multirow[t]{4}{*}{ FBN1 } & Exon 16 & c. $1875 \mathrm{~T}>\mathrm{C}$ & \multirow{4}{*}{$\begin{array}{l}\text { p. Asn625Asn } \\
\text { p. Asp2285Asp } \\
\text { p. Arg2414 } \\
\text { Termination codon }\end{array}$} \\
\hline & & & & Exon 56 & c. $6855 \mathrm{~T}>\mathrm{C}$ & \\
\hline & & & & Exon 59 & c. $7240 \mathrm{C}>\mathrm{T}$ & \\
\hline & & & & & & \\
\hline & & & ACTA2 & & None & None \\
\hline \multirow[t]{4}{*}{ Case two } & \multirow[t]{4}{*}{32} & \multirow[t]{4}{*}{34} & FBN1 & Exon 56 & c. $6725 \mathrm{G}>\mathrm{A}$ & \multirow[t]{3}{*}{ p. Arg2242His } \\
\hline & & & & Exon 02 & c. $12-27$ del GCGT & \\
\hline & & & & & CTGCTGGAGATC & \\
\hline & & & ACTA2 & & None & None \\
\hline
\end{tabular}

FBN1, fibrillin 1; ACTA2, actin, aortic smooth muscle.

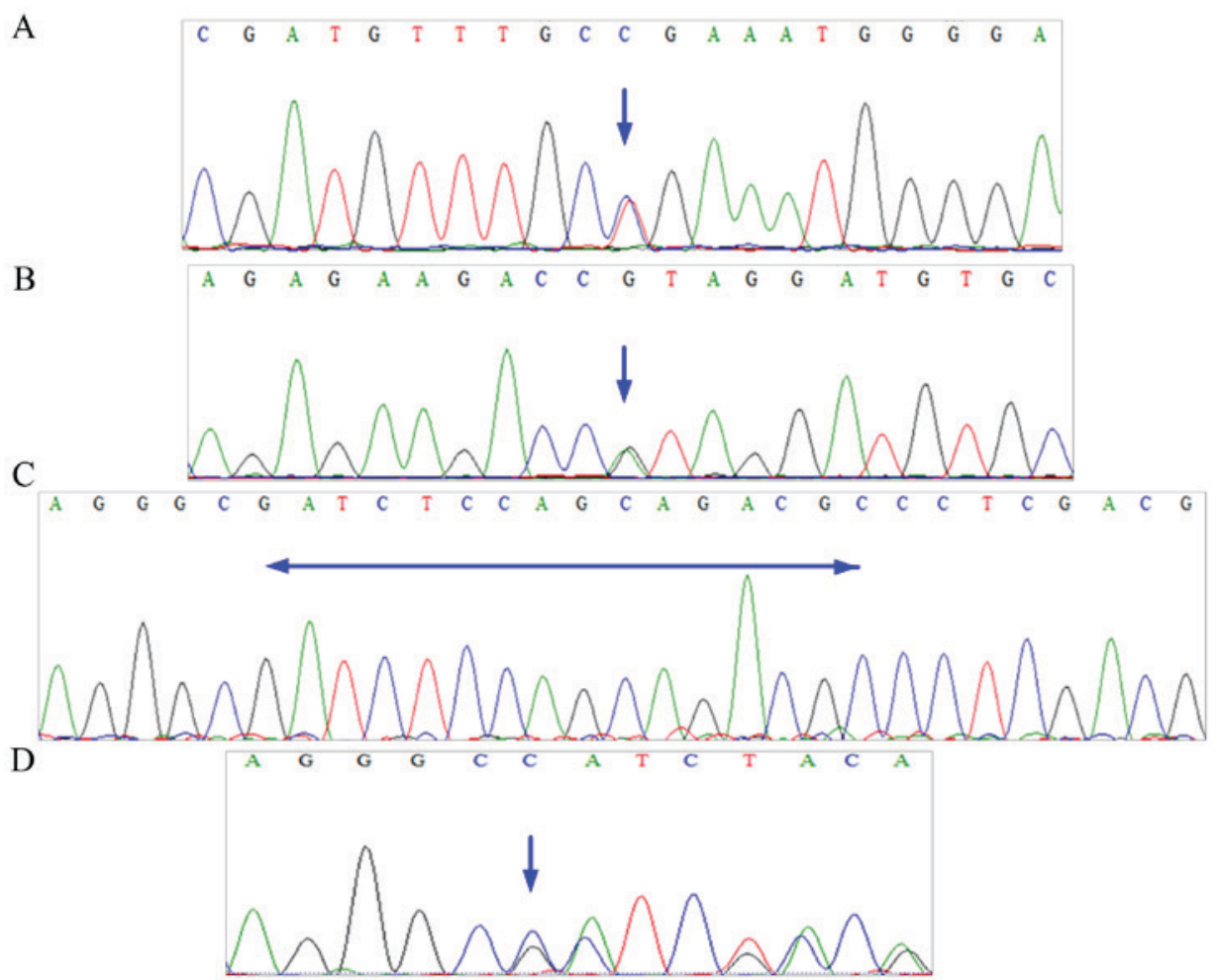

Figure 3. Sequencing peak map for the fibrillin-1 gene with pathogenic mutations. (A) Pathogenic mutation Exon 59, c. $7240 \mathrm{C}>\mathrm{T}$ (arrow) of the first patient. (B) Pathogenic mutation Exon 56, c.6725 G > A (arrow) of the second patient. (C) Exon 02, c. 12-27 (arrow) with the wild-type nucleotide from the 31-year-old female. (D) Pathogenic mutation Exon 02, c. 12-27 del GCGTCTGCTGGAGATC of the second patient; the position of base C (arrow) was the deletion starting point.

Exon 56, c. $6725 \mathrm{G}>\mathrm{A}$ (p. Arg2242His) and Exon 02, c. 12-27 del GCGTCTGCTGGAGATC (Table I). Both mutations were pathogenic (Fig. 3B-D). Finally, the healthy patient and infant male were uneventfully discharged on postoperative day 36 .

\section{Discussion}

Type A AD comprises the ascending aorta, De Bakey type I (ascending plus descending) and De Bakey type II (ascending only), and is a life-threatening but relatively rare complication of pregnancy $(1,7)$. Immer et al (1) previously reported that the incidence of pregnancy Type A dissection was $0.34 \%$ at the Mayo Clinic (Rochester, MN, USA) and $1.45 \%$ at University Hospital Berne (Berne, Switzerland) in AD patients. Previous reports also indicated that the annual incidence of $\mathrm{AD}$ was 5.5 per million maternities in the US (among 6,566,826 pregnancies in 4,933,697 females) and 0.5 per million maternities in Europe $(341,381$ females were followed up after 10 years) $(3,4)$. The mortality rate for untreated proximal AD increases by $1-3 \%$ per $\mathrm{h}$ following presentation (6). The mortality prior to admission was $21.4 \%$ and up to $60.7 \%$ at 1 day, $75.0 \%$ at 2 days and $85.7 \%$ at 1 week (9). 


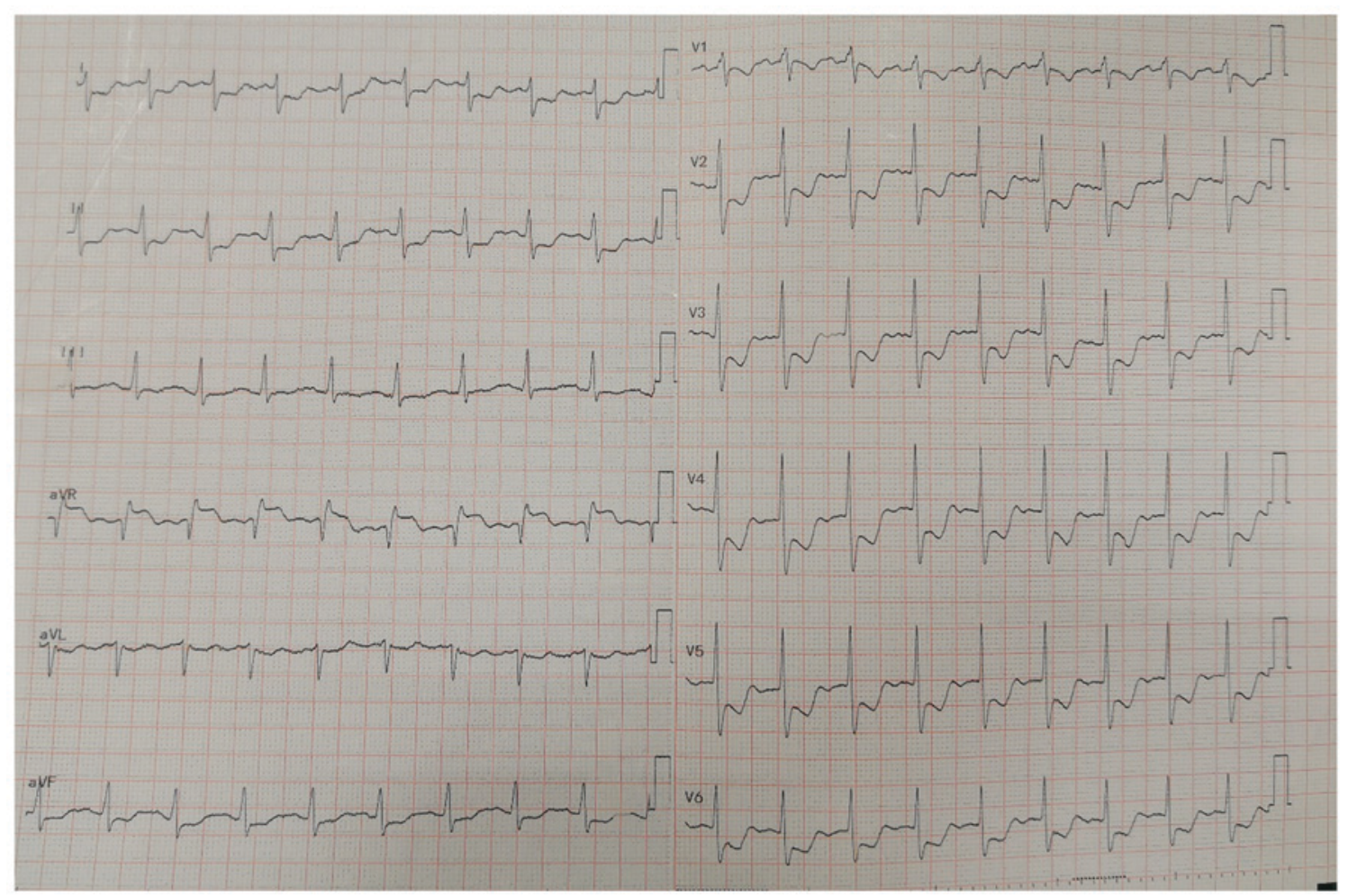

Figure 4. Electrocardiogram presents a sinus rhythm with a rate of 115 beats/min and signs of ischaemic changes (the ST segment depression of lead I, II, avF and V1-V6 and ST segment elevation of lead avR).
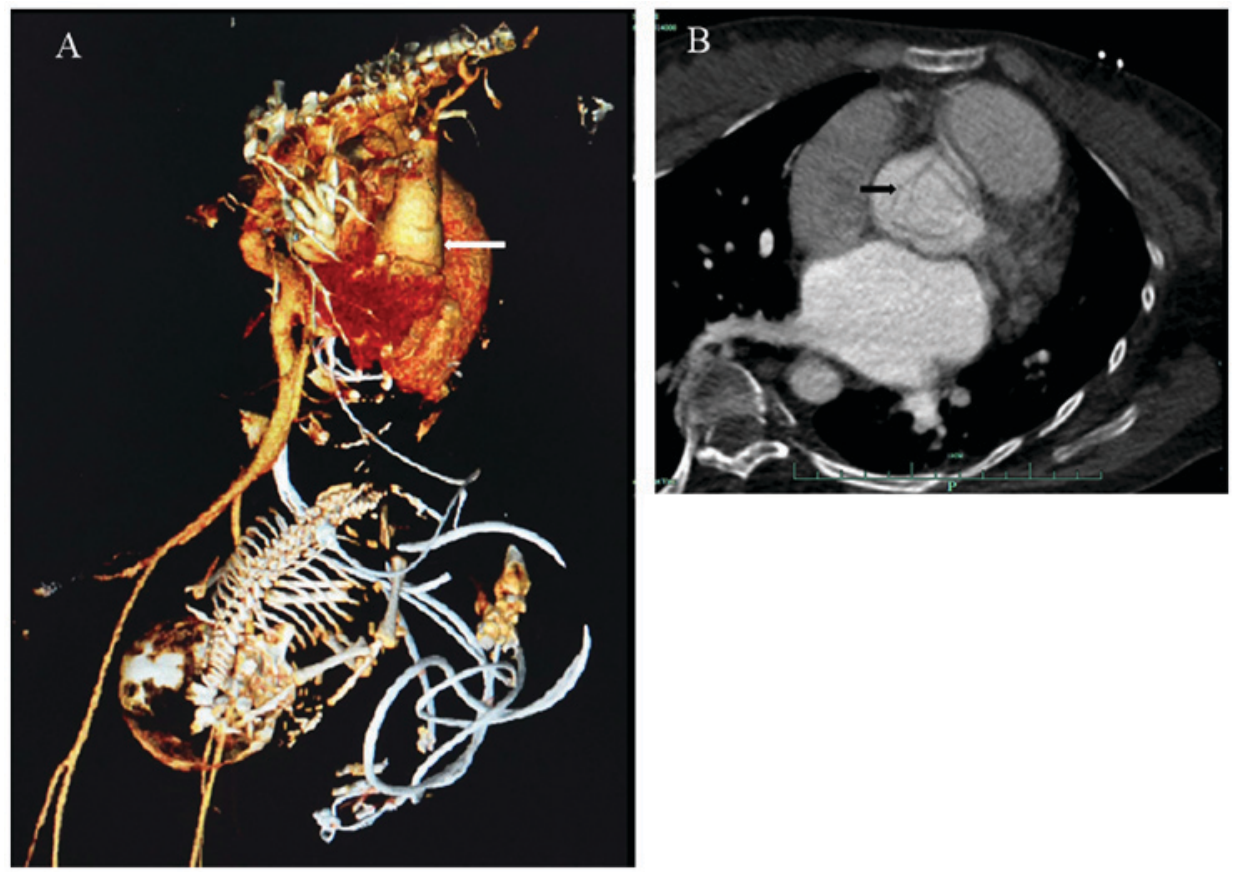

Figure 5. Sagittal (A) reconstructed and (B) standard CT images of a 32-year-old female patient who sustained an acute type A aortic dissection (DeBakey type II) at $34+1$ weeks of gestation. The Sagittal reconstructed CT indicated that the aortic root was enlarged, and the size was $52 \mathrm{~mm}$ (left arrow). The standard CT indicated that the intimal flap (right arrow) was in the aortic root. CT, computed tomography.

Pregnancy was associated with a 4 -fold risk of AD compared with the control period within 1 year following delivery (3). The ages ranged from 22 to 43 years with a mean age of 31.0 years, and the gestational age ranged from 8-38 weeks with a mean gestation of 28.7 weeks [summarized data from 30 cases presented in Table II $(2,4,6,8,11,15-21)]$. ADs in pregnancy were predominantly Type A dissection $(\sim 80 \%)(1,5,7,8)$ as the gravid uterus induces significant compression of the aorta and iliac arteries, particularly in the supine position. This possibly increases the outflow resistance 


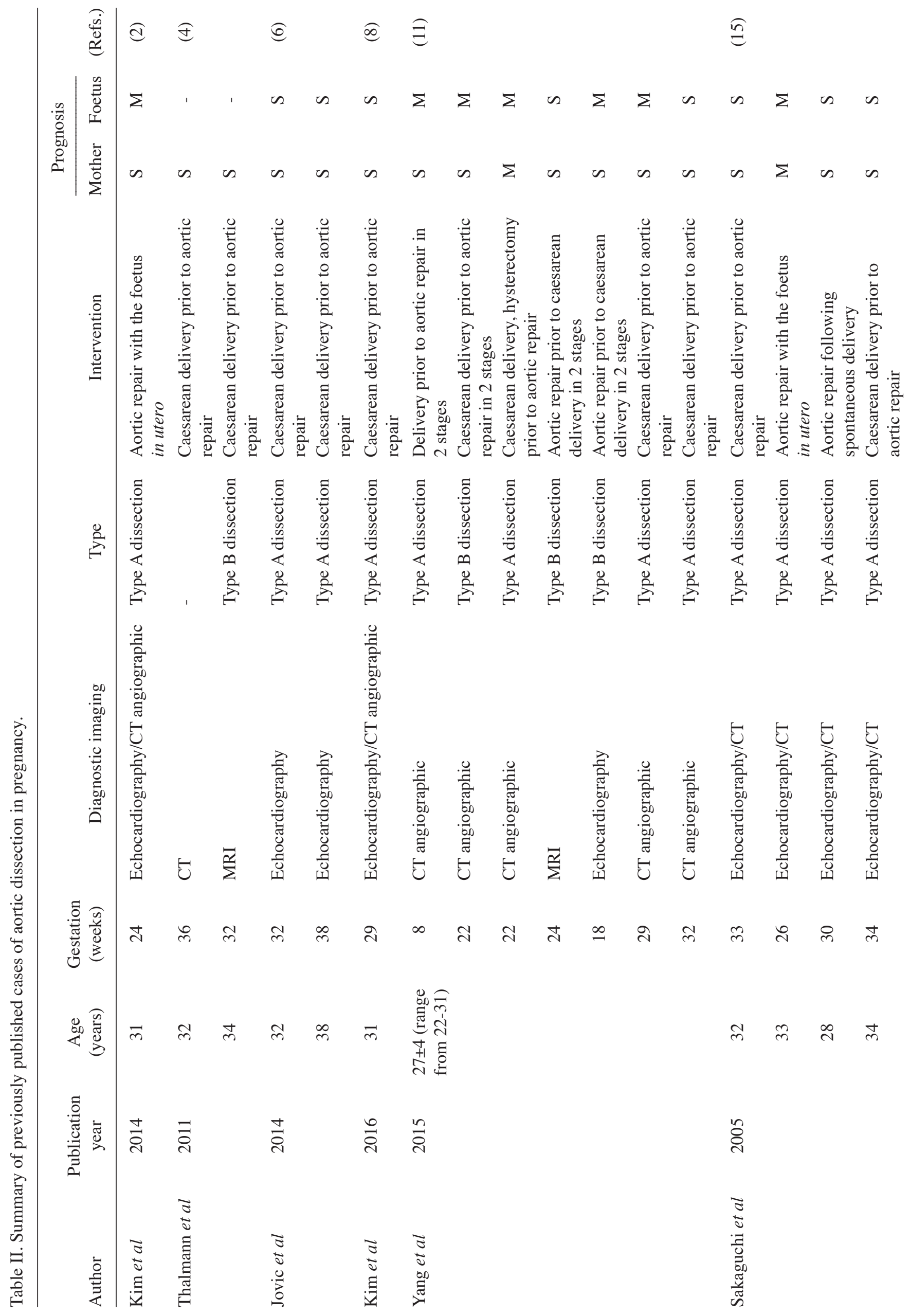




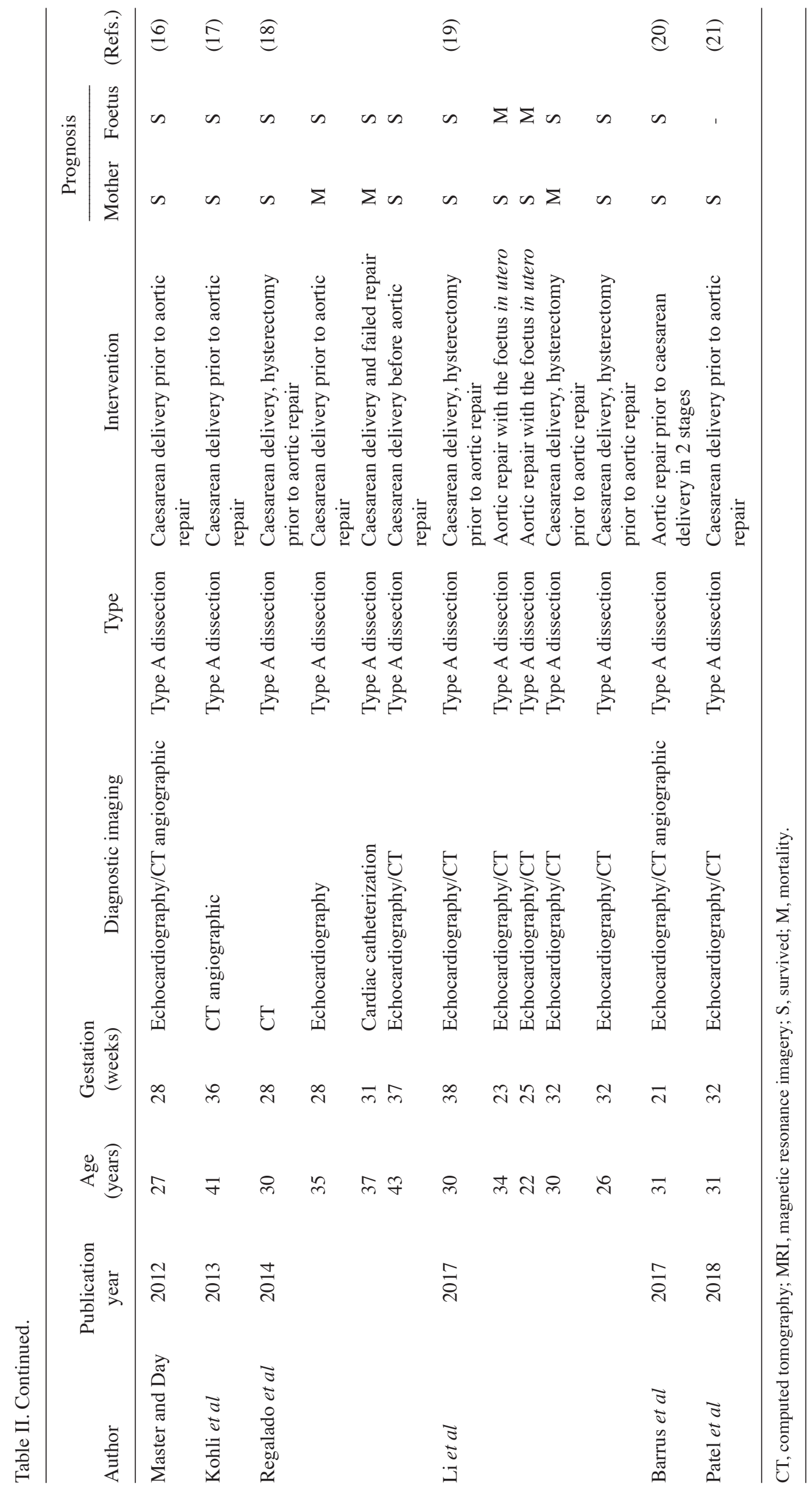


of the lower arterial tree. Hence, the upper aorta may be further predisposed to initiate an intimal tear (1). AD in pregnancy occurred in the late second or third trimester, which was correlated with increased capacity $(7,11)$. Hypertension was exhibited in $<20 \%$ of patients, but this was a risk factor for pregnancy-triggered AD (3).

Due to the indeterminacy as to whether conventional clinical imaging examination (such as X-ray and CT scans) causes harm during pregnancy, echocardiography, with its non-invasive, quick, safe, and highly sensitive characteristics and its specific imaging capability, was the recommended method for diagnosing $\operatorname{AD}(6,22)$. A literature review was performed using the Pubmed database (https://www.ncbi .nlm.nih.gov/pubmed/). The key words used in the search were 'aortic dissection' and 'pregnant'. The inclusion criterion was that the case report or the original study, for which the author provided the clinic data, must have been published in or after 2005. Studies were excluded if the personal information, diagnostic imaging or intervention method were not clear. The discrepancies between reviewers were solved by discussing the study and voting. From the present review of the literature demonstrated in Table II, echocardiography was used in 19/30 patients for the diagnosis of AD in pregnancy. The sensitivity and specificity of transthoracic echocardiography were $59-85$ and $63-96 \%$, respectively (22). It is notable that the sensitivity and specificity of transesophageal echocardiography can be up to $97-100$ and $98-100 \%$, respectively (22). Both of the present patients were diagnosed by echocardiography. In addition, magnetic resonance imaging (MRI) may be considered as a reasonable diagnostic tool when echocardiography is negative. In Japan, abdominal pain guidelines state that MRI can be recommended when ultrasounds are negative for pregnancy (23). Review of the literature revealed that 2/30 patients with AD in pregnancy were diagnosed by MRI (Table II). One meta-analysis of 7 studies revealed that the sensitivity and specificity of MRI were 98 and 98\%, respectively (24). At a minimum, CT angiography, a vital imaging test for AD, can reveal true and false cavities and the fracture position of the intima $(10,25,26)$. Hence, it is generally accepted that for $\mathrm{AD}$ in pregnancy, the reasonable diagnostic imaging order is echocardiography, MRI and then CT/CT angiography $(7,11)$. For safety, certain patients, including those described in the present study, when AD is diagnosed by echocardiography, the diagnosis requires further confirmation by $\mathrm{CT}$ angiography prior to aortic surgery.

Genetic screening can indicate whether a patient is at risk of AD. Up to $50 \%$ of ADs in pregnancy occur in patients with Marfan syndrome $(1,7,8,11)$. Patients with Marfan syndrome have a mutation in FBN1 on chromosome 15q21 $(1,8)$. Both of the present patients exhibited mutations in FBN1 that resulted in amino acid changes. The first patient had a c. $7240 \mathrm{C}>\mathrm{T}$ (p. Arg2414 Termination codon) mutation, and the second patienthad ac. $6725 \mathrm{G}>\mathrm{A}$ (p. Arg2242His) mutation. The second patient also had a c. 12-27 del GCGTCTGCTGGAGATC. These mutations have not been previously reported, to the best of our knowledge. Hence, these were novel pathogenic mutations. Regalado et al (18) previously demonstrated that ACTA2 mutations were correlated with AD in pregnancy. The rate of peripartum AD in women with ACTA2 mutations was much higher than the population-based frequency of peripartum AD
(20: 0.6\%) (18). Neither of the present patients, however, had ACTA2 mutations.

In general, once a patient is diagnosed with a Stanford type A dissection, emergency surgery should be the recommendation. Mainly according to the gestational age in weeks, aortic repair and delivery order should be decided, similar to the present patients. The first patient underwent aorta repair followed by caesarean section, and the second patient underwent caesarean section followed by aorta repair.

\section{Acknowledgements}

Not applicable.

\section{Funding}

No funding was received.

\section{Availability of data and materials}

The datasets used and/or analysed during the current study are available from the corresponding author on reasonable request.

\section{Authors' contributions}

YL, SC and GH designed the present study. YL, ZJ and JC drafted the manuscript. YL, ZJ, JC and DW collected the clinical and imaging data. YL, JC and DW performed the literature review. YL, SC and GH were major contributors in writing and revising the manuscript. All authors read and approved the final manuscript.

\section{Ethics approval and consent to participate}

Not applicable.

\section{Patient consent for publication}

Both patients provided informed written consent.

\section{Competing interests}

The authors declare that they have no competing interests.

\section{References}

1. Immer FF, Bansi AG, Immer-Bansi AS, McDougall J, Zehr KJ, Schaff HV and Carrel TP: Aortic dissection in pregnancy: Analysis of risk factors and outcome. Ann Thorac Surg 76: 309-314, 2003.

2. Kim SW, Kim D and Hong JM: Acute aortic dissection in pregnancy with the marfan syndrome. Korean $\mathrm{J}$ Thorac Cardiovasc Surg 47: 291-293, 2014.

3. Kamel H, Roman MJ, Pitcher A and Devereux RB: Pregnancy and the risk of aortic dissection or rupture: A cohort-crossover analysis. Circulation 134: 527-533, 2016.

4. Thalmann M, Sodeck GH, Domanovits H, Grassberger M, Loewe C, Grimm M and Czerny M: Acute type A aortic dissection and pregnancy: A population-based study. Eur J Cardiothorac Surg 39: e159-e163, 2011.

5. Banerjee A, Begaj I and Thorne S: Aortic dissection in pregnancy in England: An incidence study using linked national databases. BMJ Open 5: e008318, 2015. 
6. Jovic TH, Aboelmagd T, Ramalingham G, Jones $\mathrm{N}$ and Nashef SA: Type A aortic dissection in pregnancy: Two operations yielding five healthy patients. Aorta (Stamford) 2: 113-115, 2014.

7. Zhu JM, Ma WG, Peterss S, Wang LF, Qiao ZY, Ziganshin BA, Zheng J, Liu YM, Elefteriades JA and Sun LZ: Aortic dissection in pregnancy: Management strategy and outcomes. Ann Thorac Surg 103: 1199-1206, 2017

8. Kim WH, Bae J, Choi SW, Lee JH, Kim CS, Cho HS and Lee SM: Stanford type A aortic dissection in a patient with Marfan syndrome during pregnancy: A case report. Korean J Anesthesiol 69: 76-79, 2016.

9. Mészáros I, Mórocz J, Szlávi J, Schmidt J, Tornóci L, Nagy L and Szép L: Epidemiology and clinicopathology of aortic dissection. Chest 117: 1271-1278, 2000.

10. JCS Joint Working Group: Guidelines for diagnosis and treatment of aortic aneurysm and aortic dissection (JCS 2011): Digest version. Circ J 77: 789-828, 2013.

11. Yang $\mathrm{P}$, Zhang J, Li Y, Wang $\mathrm{H}$ and Zheng J: Maternal and fetal outcomes with aortic dissection in pregnant patients with Marfan syndrome. Zhonghua Fu Chan Ke Za Zhi 50: 334-340, 2015 (In Chinese)

12. Shinya S, Masaru A, Akira H, Eisaku $\mathrm{H}$ and Susumu O: Development of an assay of seven biochemical items, HbAlc, and hematocrit using a small amount of blood collected from the fingertip. Clin Chim Acta 413: 192-197, 2012.

13. Lei Y, Zheng MH, Huang W, Zhang J and Lu Y: Wet beriberi with multiple organ failure remarkably reversed by thiamine administration: A case report and literature review. Medicine (Baltimore) 97: e0010, 2018.

14. Lei $\mathrm{Y}$, Xiao $\mathrm{S}$, Chen $\mathrm{S}$, Zhang $\mathrm{H}$, Li $\mathrm{H}$ and $\mathrm{Lu} \mathrm{Y}$ N,N-dimethylformamide-induced acute hepatic failure: A case report and literature review. Exp Ther Med 14: 5659-5663, 2017.

15. Sakaguchi M, Kitahara H, Seto T, Furusawa T, Fukui D, Yanagiya N, Nishimura K and Amano J: Surgery for acute type A aortic dissection in pregnant patients with Marfan syndrome. Eur J Cardiothorac Surg 28: 280-285, 2005.

16. Master M and Day G: Acute aortic dissection in pregnancy in a woman with undiagnosed marfan syndrome. Case Rep Obstet Gynecol 2012: 490169, 2012

17. Kohli E, Jwayyed S, Giorgio G and Bhalla MC: Acute type a aortic dissection in a 36-week pregnant patient. Case Rep Emerg Med 2013: 390670, 2013.

18. Regalado ES, Guo DC, Estrera AL, Buja LM and Milewicz DM: Acute aortic dissections with pregnancy in women with ACTA2 mutations. Am J Med Genet A 164A: 106-112, 2014.
19. Li X, Zhang HY, Han FZ, Yu CJ, Fan XP, Fan RX and Zhuang J: Surgical management of pregnancy-associated acute Stanford type A aortic dissection: Analysis of 5 cases. Nan Fang Yi Ke Da Xue Xue Bao 37: 1555-1558, 2017 (In Chinese).

20. Barrus A, Afshar S, Sani S, LaBounty TG, Padilla C, Farber MK, Rudikoff AG and Hernandez Conte A: Acute type A aortic dissection and successful surgical repair in a woman at 21 weeks gestational pregnancy with maternal and fetal survival: A case report. J Cardiothorac Vasc Anesth 32: 1487-1493, 2018.

21. Patel PA, Fernando RJ, MacKay EJ, Yoon J, Gutsche JT, Patel S, Shah R, Dashiell J, Weiss SJ, Goeddel L, et al: Acute type A aortic dissection in pregnancy-diagnostic and therapeutic challenges in a multidisciplinary setting. J Cardiothorac Vasc Anesth 32: 1991-1997, 2018.

22. Yang Y: The value of echocardiography in diagnosis and treatment of aortic dissection. J Cardiovasc Surg (Electron Ed) 2: 61-63, 2013.

23. Mayumi T, Yoshida M, Tazuma S, Furukawa A, Nishii O, Shigematsu K, Azuhata T, Itakura A, Kamei S, Kondo H, et al: The practice guidelines for primary care of acute abdomen 2015. Jpn J Radiol 34: 80-115, 2016.

24. Shiga T, Wajima Z, Apfel CC, Inoue T and Ohe Y: Diagnostic accuracy of transesophageal echocardiography, helical computed tomography, and magnetic resonance imaging for suspected thoracic aortic dissection: Systematic review and meta-analysis. Arch Intern Med 166: 1350-1356, 2006.

25. Zhao H, Wen D, Duan W, An R, Li J and Zheng M: Identification of CTA-based predictive findings for temporary and permanent neurological dysfunction after repair in acute type A aortic dissection. Sci Rep 8: 9740, 2018.

26. Yang S, Li X, Chao B, Wu L, Cheng Z, Duan Y, Wu D, Zhan Y, Chen J, Liu B, et al: Abdominal aortic intimal flap motion characterization in acute aortic dissection: Assessed with retrospective ECG-gated thoracoabdominal aorta dual-source CT angiography. PLoS One 9: e87664, 2014.

This work is licensed under a Creative Commons Attribution-NonCommercial-NoDerivatives 4.0 International (CC BY-NC-ND 4.0) License. 